Historic, archived document

Do not assume content reflects current scientific knowledge, policies, or practices. 



\section{Stages of Development}

All fleas pass through four stages, the adult, the egg, the larva, or maggot, and the pupa, or resting stage. The adults are found on animals or hopping about on the ground. The eggs are laid by the

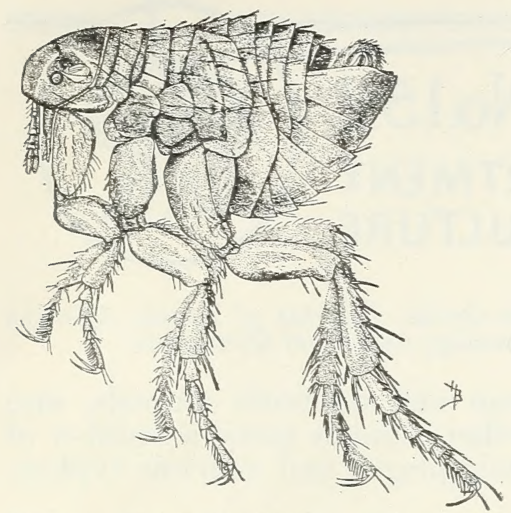

Figure 2.-Human flea (female), greatly enlarged. females while on the host and drop to the ground and hatch in a few days into legless larvae or maggots (fig. 4). In 2 weeks or more the larvae become full-grown in the dust or sand and then spin tiny cocoons, in which they change to adult fleas in the course of 1 or more weeks.

Fleas often breed in tremendous numbers in basements or outbuildings where dogs, cats, or hogs are kept. Even when dogs, eats, and other hosts are taken away, the flea maggots proceed with their development, and the resulting adults may live for several weeks without food. This accounts for the frequency with which people find their homes overrun with fleas when they return from a summer vacation.

\section{Control of Fleas on Animals}

Dogs and cats can be kept practically free of fleas by occasionally applying derris powder next to the skin along the back and neck and on top of the head. If animals have free run, this treatment must be repeated every 2 weeks. A level teaspoonful is enough to kill every flea on a large dog. For smaller animals the amount should be reduced according to the size of the animal. Most derris powders are effective. Their insect-killing value depends largely on the amount of rotenone they contain. They should have at least 0.5 percent of rotenone. Much of the derris powder now on the market contains 4 or 5 percent of rotenone. This may be diluted with talcum powder so as to bring the rotenone content down to 1 percent. Derris kills slowly; do not expect to see the fleas drop off dead immediately after an application.

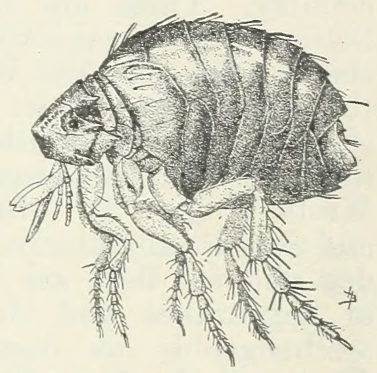

Figure 3.-Sticktight flea (female), greatly enlarged.

If derris is not at hand, fresh finely ground pyrethrum powder (insect powder) may be used as a dust. Pyrethrum powder should contain not less than 0.9 percent of pyrethrins; these are the insecticidal principles of pryethrum.

Neither derris nor pyrethrum is considered poisonous to domestic animals, although cats are sometimes thrown off their feed by licking the material from the coat.

In areas where the human flea abounds, in addition to treating the dogs and cats as outlined above, hogs should be kept from barns and 
from going beneath houses. Their backs should be lightly sprinkled with crankcase oil or crude petrolemm every 2 or 3 weeks.

If fleas are properly controlled on animals, house and yard infestations will be avoided.

\section{Destroying Fleas in Houses and Outbuildings}

Fleas in houses and barns originate in the sleeping places of animals. If these are in cellars, in outbuildings, or beneath buildings or porches, spraying the infested areas with creosote oil with a good force pump is most satisfactory. A compressed-air sprayer, or, better, a bucket pump, with a lead of high-pressure hose with tight connections, should be used.

Creosote oil will burn animals and plants. It has an objectionable odor and will stain. Therefore it cannot be used in every situation. It is not necessary to spray the walls of a cellar or outbuilding. Creosote oil is relatively cheap (50 cents to $\$ 1$ per gallon) and is generally available, since it is commonly used as a wood preserver. It is remarkably effective against fleas. Usually one light spraying will wipe out an infestation. One-half gallon is suffi-

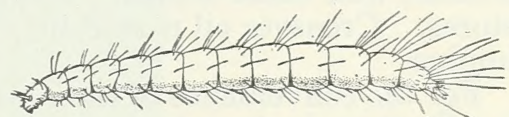

$\rightarrow$

Figure 4.-Larva, or maggot, of a flea, greatly enlarged.

cient for 1,000 square feet of floor surface. More is required for dirt floors with cracks or where much dust or litter is present.

When fleas are found to be breeding in hog pens or barns, the litter should be raked up and scattered on fields, or burned, before the spray is applied or after a preliminary spraying to give relief while cleaning up.

If fleas are abundant in living quarters, scatter flaked naphthalene over the floor of each infested room at the rate of 5 pounds per room. Keep the room closed for 24 to 48 hours. The remaining naphthalene crystals may be swept up and put in a tight container for future use. If animals have been sleeping on overstuffed furniture, it also should be covered with the naphthalene.

In cases where the main trouble is in the basement, the creosote oil spray applied there will usually give immediate relief. The scattered fleas carried into the living rooms may be destroyed with a commercial fly spray applied with an atomizer.

As soon as the premises have been treated as described, the treatment of the dogs and cats with derris powder should be begun.

Occasionally fleas will spread from infested outbuildings or basements to the yard and lawn. Treatment of the breeding places and keeping the lawn closely cut will usually meet this situation. Fleas do not live long when exposed to sunshine and rains.

Prevention of house infestations by keeping fleas off animals is not difficult, and pets are much relieved if they are kept free of fleas.

\section{Sticktight Flea Control}

Sticktight or chicken fleas are often troublesome in the South. They infest poultry, cats, dogs, rats, and other animals, and annoy man. The adult fleas attack the heads of their hosts principally and 
remain attached for weeks without changing position. The edges of the ears of dogs and cats are often covered with them.

These fleas can be controlled by keeping the roosting and nesting places of poultry clean and by spraying the dropping boards, nests, and floor of the chicken house with creosote oil. Fowls should be kept from beneath buildings, or such places should be sprayed with creosote oil every 2 or 3 weeks. If this is done, treatment of the fowls is not necessary. Derris powder or carbolated vaseline will kill the fleas. When derris is applied to dogs and cats to control this flea, it must be brought in contact with the insects, as the sticktights do not move around and come in contact with the powder.

\section{Where Insecticides May be Obtained}

Derris powder, or proprietary powders containing derris extract, and pyrethrum powder are now available in many drug, seed, petanimal, and other stores. Naphthalene flakes are handled by drug stores. Creosote oil is sold by many dealers in paint, hardware, and lumber.

For the convenience of those who are unable to obtain derris powder locally there is given below a list of some of the wholesalers and manufacturers of derris. No claim is made that the list is complete, nor is any guarantee here expressed or implied for the products of the companies listed.

Chipman Chemical Co., Bound Brook, N. J.

Wm. Cooper \& Nephews, Inc., 1909-25 Clifton Avenue, Chicago, Ill.

W. J. Dennis, 1540 Tenth Street, Des Moines, Iowa.

Derris, Inc., 79 Wall Street, New York, N. Y.

L. W. Dumont \& Co., 50 East Forty-second Street, New York, N. Y.

Hammond Paint and Chemical Co., Inc., Beacon, N. Y.

McCormick \& Co., Baltimore, Md.

S. B. Penick \& Co., 115 Fulton Street, New York, N. Y.

R. J. Prentiss \& Co., Inc., 100 Gold Street, New York, N. Y.

Sherwin-Williams Co., Chicago, Ill.

Stanco, Inc., 2 Park Ávenue, New York, N. Y.

Cyrus Ward \& Co., Ltd., 305 East Forty-seventh Street, New York, N. Y.

The market price of derris varies with the available supply and the amount purchased, but it usually sells at wholesale for about 20 to 50 cents a pound for powder containing from 4 to 5 percent of rotenone. 

